DOI: $10.20472 / S S .2018 .7 .2 .001$

\title{
ASSESSMENT OF HOUSING SATISFACTION AMONG IRANIAN IMMIGRANT'S HOMEOWNERS IN KUALA LUMPUR, MALAYSIA
}

\author{
BAHARE FALLAHI
}

\begin{abstract}
:
This study evaluated housing satisfaction of Iranian immigrants homeowners in Kuala Lumpur, Malaysia, with twenty eight variables grouped into two components -dwelling features and dwelling services. Findings from the study indicate that the residents are satisfied with housing. Socio economic characteristics of the residents such as length of time have been in Malaysia, number of bed rooms, price of residential unit, and total earned income earner are correlated with housing satisfaction, whereas age, size of household, and number of children, are not correlated with housing satisfaction. A Multiple Linear Regression (MLR) model has been estimated for the study and the model provides $57 \%$ explanations to determine housing satisfaction. The high beta coefficients of the model propose that housing satisfaction of Iranian immigrant's homeowners can be enhanced through improving the dwelling features and dwelling services. Similarly, the future dwelling should as well consider their space, design and other constructions in order to improve quality of life of the Iranian immigrant's homeowners in the Malaysia. The main goal of this study to examine the key factors whose developments can improve housing satisfaction level of the inhabitants.
\end{abstract}

\section{Keywords:}

Housing satisfaction, Dwelling features, Dwelling service, Socio- economic characteristic.

\section{Authors:}

BAHARE FALLAHI, university Putra Malaysia , Iran (Islamic Republic of), Email:

fallahi.bahare@yahoo.com

\section{Citation:}

BAHARE FALLAHI (2018). Assessment of housing satisfaction among Iranian immigrant's homeowners in Kuala Lumpur, Malaysia . International Journal of Social Sciences, Vol. VII(2), pp. 1-16., 10.20472/SS.2018.7.2.001 


\section{Introduction}

The preparation of suitable accommodation that meets government established standards of quality and consumers' desires and needs has always been the aim of housing policy in Malaysia. Fatoye and Odusami (2009) proposed that for housing segment to develop the quality of accommodation it produces, it must search and recognize consumers' desires and needs as well as the extent to which such aspirations are met via arranged performance assessment. Teck-Hong (2011) indicated that one conceivable procedure to meet family's accommodation needs is to investigate features which account for inhabitants' satisfaction or dissatisfaction with their accommodation situations. These perspectives no skepticism emphasis the need for researches on Residential satisfaction in the search to prepare accommodation that meets the daily desires, aspirations and preferences of the inhabitants. Housing satisfaction has been a subject of examined through researchers in the arena of housing. Also, residential satisfaction has been defined as a measure of inhabitants' satisfaction by both their dwelling units and neighborhood (Gaster, 1987; Hashim, 2003; Ogu, 2002), moreover, residential satisfaction has been viewed as an evaluation of the amount to which the current accommodation environment of inhabitants is meeting their aspirations and desires (Mohit, Ibrahim, \& Rashid, 2010; Salleh, 2008). Consequently, several researches on the issue (including Ibem \& Amole, 2012; Jiboye, 2009; Mohit \& Azim, 2012; Mohit et al., 2010; Salleh, 2008) are dedicated to the evaluation of the extent to which individuals are satisfied or dissatisfied with their accommodation situations, whereas others (Galster, 1987; Jaafar,Hasan, Mahamad, \& Ramayah, 2006; Jiboye, 2010; Salleh, Yosuf, Salleh, \& Johari, 2012; Tech-Hong, 2011) emphasis on the features that effect housing satisfaction in the different countries. Firstly, findings of these studies help us to understand the importance of housing characteristics, dwelling unit support amenities and neighborhood as well as the socio economic characteristics of inhabitants in housing satisfaction. Secondly, they contribute to expanding our comprehension of the dwelling aspirations and desires of persons and how they assess their accommodation surroundings in a given context. Also, these researches as well assist us to recognize that features inside and outside the dwelling amplitude have considerable effect on housing satisfaction. In spite of these understandings provided through the current researches, there is few or no concurrence in the literature on the generic pattern of residential satisfaction and the particular features that effect it across several socio demographic groups in the various areas and cultures. Moreover, there is a drib of research on the diversity in housing satisfaction amongst inhabitants of dwelling built using diverse strategies, particularly in the developing countries. The differences in socio demographic characteristics of the inhabitants, quality of housing, propose that there could be diversities in housing satisfaction amongst inhabitants in dwelling delivered using diverse strategies and those obtained via diverse processes in a specific country, area or neighborhood. The main goal of this study to examine the key factors whose developments can improve housing satisfaction level of the inhabitants.

Consequently, the following objectives have been set for the research:

To investigate the level of housing satisfaction/dissatisfaction perceived by the Iranian homeowners in Malaysia. 
To investigate the elements and kinds of facilities which influence the housing satisfaction level of the residents; and

To investigate the key factors whose improvements can develop housing satisfaction level of the residents.

\section{The review of literature and conceptual framework}

Researches on housing satisfaction serve several objectives, containing the evaluation of inhabitants' current accommodation situations, desires and needs ( Salleh, 2008) and their life quality (Caldieron, 2011; Galster \& Hesser, 1981; Lee \& Park, 2010); the level of achievement or refraction of dwelling projects (Liu, 2003; Mohit \& Nazyddah, 2011) and quality of project (Lara \& Bekker, 2012). They as well assist in developing our comprehension of dwelling adjustment and movement behaviors of inhabitants (Fang, 2006). Therefore, it can be concluded that even although individuals who conduct study on housing satisfaction have diverse rationales and purposes, researches on housing satisfaction enhance better comprehension of the key foundations of satisfaction or dissatisfaction amongst inhabitants, features that efficacy their level of satisfaction and how they are most likely to respond in the occurrence that they felt dissatisfied with their housing situations. Fang (2006), argued that this knowledge is significant in notifying Policy of housing. Different researchers and scholars put forward some theoretical and conceptual approaches in order to understand housing satisfaction Galster (1987) investigated that most researches on housing satisfaction are based purposive approach and the actual -aspiration gap approach. Galster (1985) investigated that individual are seen to have aims and goals in the direction of attaining such objectives, and that the level to which one's residential surroundings is perceived to be enabling the attainment of his/her objectives is seen as a symptom of housing satisfaction. The inference of this is that persons obtain dwelling with the aspirations that it will contribute to the reach of particular objectives in life; and therefore they see their dwellings as a property able of assisting overall attainment of their goal in life. Consequently, the level to which inhabitants perceive their accommodation is performing the 'facilitator role' is understood as a degree of housing satisfaction. Also, Galster (1987) indicated that persons create a commission quality or quantity that is "an ideal standard" of the diverse characteristics of their residential condition based on their desires and needs. Consequently, people tend to assess their dwelling situations based on the "ideal standard" which they have previously constructed a mental image of and desire to have. If their present accommodation condition is perceived to be in close congruity with to the reference condition, inhabitants tend to declare satisfaction and vice versa. It means that in the actual-desire gap approach, a gap among what persons want and desire to have and what they presently have in terms of their accommodation situations is seen as a degree of housing satisfaction. The foregoing goes to propose that inhabitants' assessment of their accommodation situations depends basically on the meaning inhabitants attach to their accommodation, standard of reference situation to which they compare it by and their accommodation desires and needs. Based on these approaches, some studies have examined the level to which inhabitants are satisfied with their dwelling units and neighborhood in the different countries. For instance, Liu (1999) examined residential 
satisfaction amongst inhabitants of public housing in Hong Kong,and showed inhabitants had high level of dissatisfaction with neighborhood facilities such as access to public transport and cleanliness of the neighborhood. In South Korea, Ha (2008) investigated that around 51 percent of the inhabitants were generally satisfied with their accommodation situations. Also, he found that the inhabitants were satisfied with neighborhood facilities such as nearness to shopping Centre, medical center, and post office. However, they were dissatisfied with public facilities such as parking facilities. Another research by Mohit and Azim (2012) found that inhabitants had higher satisfaction level for facilities and services than dwelling unit feature such as space and social environment. Ukoha and Beamish (1997), in Nigeria, found that inhabitants were satisfied with neighborhood facilities but dissatisfied with dwelling unit features. Other researches (Jiboye, 2009; Olatubara \& Fatoye, 2007) however found that the inhabitants in Lagos, Nigeria were most satisfied with dwelling unit features and least satisfied with neighborhood facilities. Clement and Kayode (2012) in Ondo State, Nigeria found that inhabitants had high level of satisfaction with neighborhood facilities and dwelling features such as size of living room and access to worship centers. Besides these researches, others have examined the features which impact housing satisfaction. For example, Ibem and Amole (2012) and Lu (2002) investigated age as one of the most important predictors of housing satisfaction. He found that the younger persons are likely to be less satisfied with their dwelling situations than the older persons. Also, level of income has been identified as having influence on housing satisfaction.

Vera-Toscano and Aceta-Amestoy (2008) investigated that inhabitants of high income group are more likely to be satisfied with their dwelling condition than persons of lower income for the reason that people with high level income has the financial power to obtain better accommodations. The impact of family size and length of stay on housing satisfaction has also been identified by scholars. For example, Mohit et al. (2010) identified there was a negative association among family size and housing satisfaction. However, he found that the length of stay in the dwelling had positive influence on housing satisfaction, in Malaysia. However, little is known of the differences in satisfaction amongst the immigrant's homeowners in another country with different culture. This research was an attempt to bridge this gap. Also from the existing research, we observe that many studies have developed housing satisfaction models based on features that are related to the context and objective of their study (see Fang, 2006; Mohit \& Nazyddah, 2011; Tech-Hong, 2011). Following this tradition, the conceptual framework of this research contains elements such as dwelling unit features, dwelling unit services and demographic characteristics of the inhabitants.

\section{Conceptual model}

The conceptual model of the study is based on the perception that housing satisfaction is a compound construct of the indices of satisfaction which respondent's identify with dwelling features and dwelling services. Amerigo and Aragones (1997) investigated that objective physical characteristics of the housing, once they have been evaluated via the individual become subjective giving rise to an assurance level of housing satisfaction. 
Subjective features are influenced via the socio economic characteristics along with his/her housing characteristic pattern, a normative factor whereby the inhabitants compares her/his preferences and desires and current situation. The model indications that the respondents assessment of objective features of dwelling thru their socio economic becomes subjective features which can be captured into two aspects of housing satisfaction and these two aspects together form the basis of housing of the inhabitants.

\section{Methodology}

Dwelling differs in its layout, design, construction, space; but whatever form it captures it is essential to measure its quality to make sure that it fulfills the needs and desires of inhabitants. Quality of accommodation can be measured thru subjective and objectives features. Objective measurement evaluates dwelling features and dwelling services. However, objective estimation is not able to examine the psychosocial aspects of housing satisfaction. Subjective measurement which encompasses needs, aspiration, and also dissatisfaction is closely associated to the psychosocial aspects of a person (Nurizan \& Hashim, 2001).

\section{Selection of components and variables for housing satisfaction}

Most housing satisfaction researches have integrated both subjective and objective characteristics for the valuation of housing satisfaction. Varady and Carrozza (2000) indicated that, housing satisfaction comprises satisfaction with the dwelling unit features and satisfaction with dwelling services. Also, Oh (2000), identified the quality of dwelling and environment which impact the housing quality. Based upon the literature review on factors that are likely to affect housing satisfaction, the present research investigates the "residential satisfaction bundle" to comprise two sheltered aspects - (1) the dwelling unit features with 20 variables; and (2) dwelling unit support services with 8 variables.

\section{Dwelling unit features}

Dwelling unit features refer to the spaces in the dwelling unit such as bath rooms, bed rooms, living rooms, dining rooms and also design and construction of the dwelling unit.

Dwelling unit support services

Dwelling services refer to the space outside the dwelling unit. The factors comprised are electricity, water supply, and lifts.

\section{Sampling design}

This is a quantitative study. The questionnaire survey provided information on the housing satisfaction variables hypothesized to promote the residential satisfaction among 235 households $(n=235)$ in order to enhance the housing satisfaction. The target population 
is the Iranian immigrant's homeowners in Kuala Lumpur. Kuala Lumpur is a capital city of Malaysia. Moreover, it is the hub center of the country and has a land area of $243.65 \mathrm{~km} 2$ with it's a number of cultural and financial activities. For selecting the sample size, the researcher used Cochran proposed using equation to determine the size. In this study, systematic random sampling has been used to select the samples for questionnaire survey. Designed questionnaire was used to collect data from the respondents, the structured interview for data collection is the superior choice (Fowler,1993). The questionnaire comprises of three sectors with residents and accommodation unit information (section-1); satisfaction with dwelling unit (section-2); and satisfaction with dwelling services (section-3). The level of housing satisfaction has been measured by using a five-point Likert scale - "1" for very dissatisfied, "2" for dissatisfied, 3" for slightly satisfied, " 4 " for satisfied and " 5 " for very satisfied.

\section{Analysis and findings}

Socio-demographic characteristics of the participants

Among Iranian homeowners in Malaysia were dominantly man (69.8\%) compared to woman (30.2\%) (Appendix Table A1). Most of the homeowners (35.3\%) were between age 41 and 50, followed by the age group of below 40 (31.9\%) and the old age persons (above 61) constituted 14.1 in the sample. Though households with 3 members were dominant (26\%), $23.4 \%$ of the homeowners had 4 people in their households and $17.9 \%$ homeowners have 5 residents. The highest level of education of the homeowners was bachelor. Level of income of most (28.9\%) of the homeowners was above RM15000, followed by $27.3 \%$ whose incomes were between RM7000-10000 and $23.4 \%$ earned less than RM7000. Majority (37.4\%) of the participants' jobs were in the private segment followed by $12.8 \%$ who had their own businesses and $17 \%$ retired.

\section{Table A1}

Respondents' demographic and socio-economic characteristics

\begin{tabular}{cccccc}
\hline Variable & & $\mathbf{n}$ & $\%$ & $\mathbf{M}$ & SD \\
\hline Sex & Male & 164 & 69.8 & & \\
& Female & 71 & 30.2 & & \\
Age & & & & 47.07 & 10.95 \\
Age group & Below 40 & 75 & 31.9 & & \\
& $41-50$ & 83 & 35.3 & & \\
\hline
\end{tabular}




\begin{tabular}{|c|c|c|c|}
\hline & $51-60$ & 44 & 18.7 \\
\hline & Above 61 & 33 & 14.1 \\
\hline \multicolumn{4}{|l|}{ Level of education } \\
\hline & High School & 34 & 14.5 \\
\hline & Bachelor & 119 & 50.7 \\
\hline & Master & 41 & 17.4 \\
\hline & $\mathrm{PhD}$ & 41 & 17.4 \\
\hline \multirow{4}{*}{$\begin{array}{l}\text { occupation status of } \\
\text { first income earner }\end{array}$} & Retired & 40 & 17.0 \\
\hline & $\begin{array}{l}\text { Working for a private } \\
\text { company or person }\end{array}$ & 88 & 37.4 \\
\hline & $\begin{array}{l}\text { Working at own } \\
\text { business without } \\
\text { any employees }\end{array}$ & 30 & 12.8 \\
\hline & $\begin{array}{l}\text { Working at own } \\
\text { business and } \\
\text { employing other } \\
\text { workers }\end{array}$ & 77 & 32.8 \\
\hline
\end{tabular}

Table A1 (continued)

\begin{tabular}{cccccc}
\hline Variable & & $\mathbf{n}$ & $\%$ & $\mathbf{M}$ & SD \\
\hline Marital status & Single & 19 & 8.1 & & \\
& Married & 200 & 85.0 & \\
& Divorced & 14 & 6.0 &
\end{tabular}




\begin{tabular}{|c|c|c|c|}
\hline & Widowed & 2 & .9 \\
\hline \multirow{7}{*}{$\begin{array}{l}\text { Household } \\
\text { size }\end{array}$} & One & 19 & 8.1 \\
\hline & Two & 32 & 13.6 \\
\hline & Three & 61 & 26.0 \\
\hline & Four & 55 & 23.4 \\
\hline & Five & 42 & 17.9 \\
\hline & Six & 21 & 8.9 \\
\hline & Seven & 5 & 2.1 \\
\hline \multirow{6}{*}{$\begin{array}{l}\text { Number of } \\
\text { children }\end{array}$} & Zero & 42 & 17.9 \\
\hline & One & 63 & 26.8 \\
\hline & Two & 60 & 25.5 \\
\hline & Three & 42 & 17.9 \\
\hline & Four & 23 & 9.8 \\
\hline & Five & 5 & 2.1 \\
\hline \multirow{4}{*}{$\begin{array}{l}\text { Monthly } \\
\text { income of } \\
\text { families }\end{array}$} & $\begin{array}{l}\text { Less than } \\
7000\end{array}$ & 55 & 23.4 \\
\hline & $7000-10000$ & 64 & 27.3 \\
\hline & $10000-15000$ & 48 & 20.4 \\
\hline & Above 15000 & 68 & 28.9 \\
\hline
\end{tabular}




\section{Satisfaction with housing}

Respondents' levels of housing satisfaction with accommodation containing of 28 items presented in Table A2 show that the residents of Iranian immigrant's homeowners satisfied with their overall housing situation. the result indicates that majority of respondents $(41.3 \%)$ were satisfied with their housing, followed by $40.4 \%$ who were somewhat satisfied and very few $(2.1 \%)$ who were very dissatisfied with their current housing situation with 66.38 Mean and 12.52 Standard deviation. To support these findings, theoretical underpinnings on residential satisfaction are based on the idea that residential satisfaction measures the difference between households' actual and desired/aspired housing situations (Galster, 1985). Households usually make their judgments about residential conditions based on their needs and aspirations. Satisfaction with households' housing conditions implies the absence of any complaints and a high degree of congruence between actual and desired situations. On the other hand, incongruence between housing needs and aspirations may lead to dissatisfaction. Galster (1985) also, argued that residential dissatisfaction might result from a change in household needs, change in a particular location's social and physical amenities, or a change in the standards used to evaluate these factors. Within Galster's framework, physical amenities (or their opposite physical dis-amenities) as "locational characteristics," have the most relevance for consideration of satisfaction.

\section{Table A2}

\section{Distribution of housing satisfaction}

\begin{tabular}{|c|c|c|c|c|}
\hline Variable & $\mathbf{M}$ & SD & $\mathbf{n}$ & $\%$ \\
\hline Housing satisfaction & 66.38 & 12.52 & & \\
\hline Very dissatisfied & & & 5 & 2.1 \\
\hline Dissatisfied & & & 24 & 10.2 \\
\hline Somewhat satisfied & & & 95 & 40.4 \\
\hline Satisfied & & & 97 & 41.3 \\
\hline Very satisfied & & & 14 & 6 \\
\hline
\end{tabular}




\section{Associations between housing satisfaction components and socio-demographic characteristics of respondents}

Pearson's correlation coefficient ( $r$ ) between housing satisfaction and Socio-demographic factors (Table A3) found that housing satisfaction index is correlated with length of time owner been in Malaysia, number of bed rooms, price of residential unit, and total earned income earner. Housing satisfaction of the respondent's increases with the increase in level of income. It, thus, appears that residents' socio-economic attributes such as total earned income earner, number of bed rooms and price of residential unit are positively related to housing satisfaction. It means that with increase income, number of rooms and price of residential unit, housing satisfaction will be increase.

This finding was consistent with the findings of Liu (1999) and Vera-Toscano and AtecaAmestoy (2008) who found association between income and housing satisfaction, because people with high socio economic factor such as income can get access to more facilities to become satisfied.

Moreover, result of the bivariate correlation revealed a negative significant correlation between length of residence and housing satisfaction. This finding showed that an increase of length of residence resulted in less housing satisfaction. This significant and negative association between length of residence and housing satisfaction was in contrast with past work (Jaafar et al., 2006). Also, result of the bivariate association shown a significant association between number of bed rooms and housing satisfaction. This finding was consistent with the results of Mohit and Azim (2012). Likewise, correlation between price and housing satisfaction was consistent with the findings of (Tan,2011).He indicated that a house that is located in a good neighborhood is preferable, as households are willing to pay more for a house in a neighborhood with good environmental qualities.

\section{Table A3}

Pearson's correlation coefficient $(r)$ matrix between housing satisfaction and socio-economic characteristics of respondents

\begin{tabular}{ccc}
\hline Demographic Data & $r$ & p-value \\
\hline Size of Household & .07 & .290 \\
Number of Children & .04 & .591 \\
Number of Income Earner & .02 & .807 \\
Number of Non-Income Earner & .06 & .357 \\
\hline
\end{tabular}


Monthly Income of Second

Time Owners Have been in

Number of Bed Room

Number of Bath Room

Price of the Residential Unit $.16^{*}$ $\mathrm{P}<.05$

.428 


\section{Predictors of housing satisfaction}

Multiple Linear Regression (MLR) analysis is a method for measuring the simultaneous effects of independent variables to explain differences in the dependent variable. Multiple Linear Regression analysis has been evaluated to examine the best linear combination of variables for predicting housing satisfaction by using enter method. The exercise resulted to the choice of two variables - satisfactions with dwelling features, and dwelling services, as predictor variables to determine housing satisfaction of Iranian immigrant's homeowners.

The combination of predictor variables significantly predicted housing satisfaction of Iranian immigrants homeowners, with $\left(F_{(10,224)}=29.70, p<.001\right.$, with two variables significantly contributing to the prediction. The beta weights presented in Appendix Table A4 present that housing satisfaction with dwelling services most to predicting housing satisfaction, followed by dwelling features, which contribute housing satisfaction of the Iranian immigrants homeowners. According to the results generated, the coefficient of determination of model was .57. This means that that $57 \%$ of housing satisfaction was explained by the dwelling services and dwelling features. Also, all VIF values were smaller than 10.The findings of multicollinearity diagnostics were that there was no evidence found of multicollinearity or perfect multicollinearity among the independent variables included in the model.

As expected, results from the bivariate and multivariate analyses indicated a significant association between dwelling features and housing satisfaction. In other words, dwelling features was found to be one of the protective and significant predictors of housing satisfaction. This finding certainly supports the residential satisfaction model and residential satisfaction studies that suggest dwelling features as an important determinant of housing satisfaction among the households ( Ibem \& Amole , 2012; Mohit et al., 2010).

Other findings from this study showed that dwelling services significantly contributed toward housing satisfaction and this result tends to support studies by Jiboye (2009) and Mohit et al.(2010).

Mohit et al. (2010) found that housing services and housing features such as bed room, dining space as predictor variables significantly predicted housing satisfaction of public low cost housing. Likewise, Ibem and Amole (2013) argued that adequacy of the size of living and sleeping area as the predictor variable to determine residential satisfaction in the housing estate. Moreover, number of rooms and number of bedrooms, which are alternative of housing space or dwelling size, could affect housing satisfaction according to studies by Lu (1999), housing features such as housing space needs influence residential satisfaction. 
Table A4

Results of Multiple Regression To Predict Housing Satisfaction

\begin{tabular}{lccccccc}
\hline & \multicolumn{7}{c}{ Collinearity Statistics } \\
\cline { 2 - 7 } Variable & B & SE & Beta & $\mathbf{t}$ & Tolerance & VIF \\
\hline Constant & -12.719 & 5.568 & & -2.284 & \\
gender & 1.357 & 1.224 & .050 & 1.109 & .949 & 1.054 \\
Level of education & .081 & .618 & .006 & .131 & .898 & 1.113 \\
Total number of income earner & -1.538 & 1.032 & -.076 & -1.491 & 745 & 1.342 \\
Total earned income & .000 & .000 & .124 & 2.365 & .699 & 1.430 \\
Time owner been in Malaysia & -.032 & .361 & -.004 & -.090 & .891 & 1.122 \\
Number of bed rooms & -.182 & .970 & -.010 & -.187 & .639 & 1.566 \\
Price of residential unit & 3.479 & .000 & .062 & 1.187 & .702 & 1.426 \\
Dwelling service & .462 & .073 & .356 & $6.288^{* *}$ & .599 & 1.670 \\
Dwelling feature & .359 & .079 & .271 & $4.558^{* *}$ & .543 & 1.843 \\
\hline
\end{tabular}

\section{Conclusions}

This research has found that among Iranian homeowners in Malaysia were dominantly man compared to woman. Also, the highest level of education of the homeowners was bachelor. As well, majority of the participants' jobs were in the private segment .Most of the inhabitants in Kuala Lumpur, Malaysia were satisfied with their housing situations. Also, Pearson's correlation coefficient between housing satisfaction and Sociodemographic factors found that housing satisfaction index is associated with length of time owner been in Malaysia, number of bed rooms, price of residential unit, and total earned income earner. Moreover, dwelling features was found to be one of the protective and significant predictors of housing satisfaction. Likewise, dwelling services significant predictor of housing satisfaction. Access to dwelling services such as supply of electricity and good drinking water were the main sources of satisfaction among the inhabitants as the research suggests. Also dwelling features such as space and number of bedrooms 
were the main items of satisfaction among owners. So, this situation may have adverse implications on the life quality of the inhabitants of the housing estates.

The policy implications of the research propose that housing satisfaction and by extension the life quality of inhabitants of Iranian immigrant's homeowners in the research area, and to be sure future housing projects, can be improved via the provision of basic dwelling services and dwelling features in the housing estates. To attain this, it is significant to emphasize that future housing project for immigrants should continue to develop the quality of housing units they produce by make sure that dwellings are constructed and deigned to provide suitable dwellings for the inhabitants.

\section{References}

Amerigo, M., \& Aragones, J. M. (1997). A theoretical and methodological approach to the study of residential satisfaction. Journal of Environmental Psychology, 17, 47-57. https://doi.org/10.1006/jevp.1996.0038

Caldieron, J. (2011). Residential satisfaction in La Perla informal neighborhood, San Juan, Puerto Rico. OIDA International Journal of Sustainable Development, 2(11), 77e84.

Clement, O. I., \& Kayode, O. (2012). Public housing provision and user satisfaction in Ondo State, Nigeria. British Journal of Arts and Social Sciences, 8(1), 103e111.

Fatoye, E. O., \& Odusami, K. T. (2009). 'Occupants' satisfaction approach to housing performance evaluation: the case of Nigeria", paper presented at the RICS COBRA research conference held at the University of Cape Town, 10e11 September, downloaded from www.rics.org/cobra on February 22, 2010.

Fang, Y. (2006). Residential satisfaction, moving and moving behaviors: a study of redeveloped neighborhoods in inner-city Beijing. Housing Studies, 21(5), 671 e694. https://doi.org/10.1080/02673030600807217

Fowler, F. (1993). Survey research methods. Newbury Park, CA: Sage Publications.

Galster, G. C. (1985). Evaluating indicators for housing policy: residential satisfaction vs marginal improvement priorities. Social Indicators Research, 16(4), 415e448. https://doi.org/10.1007/BF00333289

Galster, G. C. (1987). Identifying the correlates of dwelling satisfaction: an empirical critique. Environment and Behavior, 19(5), 537e568. https://doi.org/10.1177/0013916587195001

Galster, G. C., \& Hesser, G. W. (1981). Residential satisfaction: compositional and contextual correlates. Environmental and Behaviour, 13(6), 735e758. https://doi.org/10.1177/0013916581136006

Ha, S.-K. (2008). Social housing estates and sustainable community development in South Korea. Habitat International, 32, 349e363. https://doi.org/10.1016/j.habitatint.2007.11.005

Hashim, A. H. (2003). Residential satisfaction and social integration in public low cost housing in Malaysia. Pertanika Journal of Social Science and Humanity, 11(1) 1e10. 
Ibem, E. O., \& Amole, D. (2012). Residential satisfaction in public core housing in Abeokuta, Ogun State, Nigeria. Social Research Indicators, . http://dx.doi.org/ 10.1007/s11205-012-0111-z.

Jaafar, M., Hasan, N. L., Mahamad, O., \& Ramayah, T. (2006). The determinants of housing satisfaction level: a study on residential development project by PENANG development corporation (PDC). Downloaded from. http://www. fppsm.utm.my/jurnal/JK6D06_MASTURAJAAR.pdf. on May 15, 2008

Jiboye, A. D. (2009). Evaluating tenant's satisfaction with public housing in Lagos, Nigeria. Town Planning and Architecture, 33(4), 239e247. https://doi.org/10.3846/13921630.2009.33.239-247

Jiboye, A. D. (2010). Correlates of public housing in Lagos, Nigeria. Journal of Geography and Regional Planning, 3(2), 017e028.

Lara, T., \& Bekker, M. C. (2012). Resident satisfaction as a project quality measure: the case of Nova Vida housing project, Angola. Journal of Contemporary Management, 9, 364e381.

Lee, E., \& Park, N. (2010). Housing satisfaction and quality of life among temporary residents in the United States. Housing and Society, 37(1), 43e67. https://doi.org/10.1080/08882746.2010.11430580

Liu, A. M. M. (2003). The quest for quality in public housing projects: a behavior to- outcome paradigm. Construction Management and Economics, 21(2), 147e158. https://doi.org/10.1080/08882746.2010.11430580

Liu, A. M. M. (1999). Residential satisfaction in housing estates: a Hong Kong perspective. Automation in Construction, 8, 511e524. https://doi.org/10.1080/0144619032000049700

Lu, M. (2002). Are pastures Greener? Residential consequences of migration. International Journal of Population Geography, 8, 201e216. https://doi.org/10.1002/ijpg.244

Mohit, M. A., Ibrahim, M., \& Rashid, Y. R. (2010). Assessment of residential satisfaction in newly designed public low-cost housing in Kuala Lumpur, Malaysia. Habitat International, 34, $18 \mathrm{e} 27$. https://doi.org/10.1016/j.habitatint.2009.04.002

Mohit, M. A., \& Azim, M. (2012). Assessment of residential satisfaction with public housing in Hulhumale', Maldives, ASEAN conference on environment behavior studies, Bangkok, Thailand, 16e18 July; Procedia Social and Behavioral Sciences, 00(2012),1e17. Downloaded from www.elsevier.com/locate/ procedia. on January 16, 2013.

Mohit, M. A., \& Nazyddah, N. (2011). Social housing programme of selangor zakat board of Malaysia and housing satisfaction. Journal of Housing and the Built Environment, 26(2), 143e164. https://doi.org/10.1007/s10901-011-9216-y

Nurizan, Y., \& Hashim, A. H. (2001). Perumahan dan Kediaman. Malaysia: Universiti Putra Malaysia.

Ogu, V. I. (2002). Urban residential satisfaction and the planning implications in a developing world context: the example of Benin City, Nigeria. International Planning Studies, 7(1), 37e53.

Teck-Hong, T. (2011). Housing satisfaction in medium-and high-cost housing: the case of greater Kuala Lumpur, Malaysia. Habitat International, 35(3), 1e9. https://doi.org/10.1080/13563470220112599

Oh, L.S. (2000). Housing satisfaction of middle income households in Bandar Baru Bangi, Selangor. Dissertation, Universiti Pertanian Malaysia 
Olatubara, C. O., \& Fatoye, E. O. (2007). Evaluation of the satisfaction of occupants of the Abesan public low-cost housing estate in Lagos State, Nigeria. The Nigerian Journal of Economic and Social Studies, 49(1), 5e9.

Salleh, A. G. (2008). Neighborhood factors in private low-cost housing in Malaysia. Habitat International, 32(4), 485e494. https://doi.org/10.1016/j.habitatint.2008.01.002

Salleh, A. N. A., Yosuf, B. N. A., Salleh, C. A. G., \& Johari, D. N. (2012). Tenant satisfaction

in public housing and its relationship with rent arrears: Majlis Bandaraya, Perak, Malaysia. International Journal of Trade, Economics and Finance, 2(1), 10e18.

Tan, Teck-Hong. (2011). Determinants of housing satisfaction in Klang Valley, Malaysia. School of Business Occasional Paper Series(2).

Teck-Hong, T. (2011). Housing satisfaction in medium-and high-cost housing: the case of greater Kuala Lumpur, Malaysia. Habitat International, 35(3), 1 e9.

Ukoha, O. M., \& Beamish, J. O. (1997). Assessment of resident's satisfaction with public housing in Abuja, Nigeria. Habitat International, 21(4), 445e460. https://doi.org/10.1016/S0197-3975(97)00017-9

Varady, D. P., \& Carrozza, M. A. (2000). Towards a better way to measure customer satisfaction levels in public housing: a report from Cincinnati. Housing Studies, 15(6), 797-825. https://doi.org/10.1080/02673030020002555

Vera-Toscano, E., \& Ateca-Amestoy, V. (2008). The relevance of social interactions on housing satisfaction. Social Indicators Research, 86, 257e274. https://doi.org/10.1007/s11205-007-9107-5 